\title{
Proximate factors controlling the morphologic plasticity of Bosmina: linking artificial laboratory treatments and natural conditions
}

\author{
Masaki Sakamoto • Takayuki Hanazato
}

Received: 16 March 2008/Revised: 15 July 2008/Accepted: 1 August 2008/Published online: 19 August 2008

(C) Springer Science+Business Media B.V. 2008

\begin{abstract}
Recent studies have shown that some biotic/abiotic signals such as predator-mediated chemical/physical cues and disparate water temperature are important factors for the induction of antipredator morphs in cladocerans. As much of the evidence has come from laboratory studies, it is important to investigate the extent to which these studies reproduce the real cyclomorphic conditions occurring in nature. The present study was planned to compare the differences in the potential intensity of cyclomorphogenic factors in the laboratory and in nature. For this, we conducted two experiments in the laboratory and the field at the same time using the small cladoceran Bosmina longirostris and a predacious copepod. The results of the present experiments suggested that an abiotic factor, lower temperature acted as a key factor enhancing the changes in both the length and shape of antennules in Bosmina, which had been governed by different signals from predators. The lower temperature can be effective in
\end{abstract}

Handling editor: S. I. Dodson

M. Sakamoto - T. Hanazato

Institute of Mountain Science, Shinshu University,

Kogandori 5-2-4, Suwa 392-0027, Japan

M. Sakamoto ( $\square)$

Research Center for Environmental Risks,

National Institute for Environmental Studies,

Onogawa 16-2, Tsukuba 305-8506, Japan

e-mail: mslucky94@yahoo.co.jp helping prey bosminids to detect a severe predation threat by cyclopoid copepods, since that condition is a feature of spring and fall, a time when copepods are abundant.

Keywords Cladocera Bosmina . Cyclopoid copepod - Inducible defense ·

Proximate factors

\section{Introduction}

Morphological change in response to specific predators is a common strategy in freshwater zooplankters that helps the prey animals to reduce the risk of extinction due to predation (Agrawal, 2001; Lass \& Spaak, 2003). The defenses of the prey make it more difficult for the predators to handle or ingest them, resulting in better competitive ability in the presence of particular predators compared with organisms lacking such defenses (Laforsch et al., 2004; Vos et al., 2004). In order to understand the induction process and how a particular morphological defense is effective as a survival strategy, there has been increasing interest in recent decades on the use of ecological studies on the proximate factors influencing induction (Tollrian \& Dodson, 1999).

Chemical signals, kairomones (allelochemicals giving the receivers some benefit, Brown et al., 1970), released from vertebrate/invertebrate predators have 
been considered the main proximate factors to trigger the development of protuberant morphologies (Tollrian \& Dodson, 1999). Since the kairomones dissolve in the water, prey animals can detect particular predators before they encounter them (Hanazato, 1994). Polymorphic zooplankters respond to the predator kairomones, though most of the kairomone-induced morphological changes in the laboratory have been less extreme than those in the field, suggesting that a single exposure to predator kairomones is insufficient to trigger extreme morphological modification (Havel \& Dodson, 1985; Hanazato \& Ooi, 1992; Sakamoto et al., 2006).

In the case of morphological changes in cladoceran, cyclomorphic factors other than predator kairomones have been studied in the genera Daphnia and Bosmina. As examples of predator-mediated signals, alarm substances released from crushed conspecifics are known to act as enhancers of the changes (Stabell et al., 2003; Laforsch et al., 2006). The alarm cue informs the surrounding conspecific animals that they are in a dangerous environment. An abiotic factor, warmer (or colder) water temperature, can induce defensive morphs even in the absence of predators (Havel \& Dodson, 1985; Kappes \& Sinsch, 2002). To prey cladocerans, disparate water temperature can be a stimulus identical to an abundance of predators in the field: high temperature is a feature of summer, a time when the invertebrate predator, the Chaoborus larva, appears in abundance (Tollrian \& Dodson, 1999). On the other hand, low temperature (spring and autumn) suggests to the prey that there is a high abundance of cyclopoid copepods (Tollrian \& Dodson, 1999; Kappes \& Sinsch, 2002).

Recent studies have also shown that physical cues such as the small-scale water turbulence caused by predators or their attacks are important factors for the induction of protuberant morphologies (Havel \& Dodson, 1985; Laforsch \& Tollrian, 2004; Tollrian \& Laforsch, 2006; Sakamoto et al., 2007). Surprisingly, Laforsch \& Tollrian (2004) have demonstrated that water turbulence alone induces extreme helmet formation by Daphnia cucullata even in the absence of predator kairomones (Laforsch \& Tollrian, 2004). Furthermore, Sakamoto et al. (2007) have reported that the changes in the antennule morphotypes of Bosmina longirostris are induced only by physical stimuli from the predacious copepods and not by their kairomones. The evidence from their studies suggests that physical stimuli can be a key induction factor for the development of defensive devices in cladocerans, in addition to any role of kairomones.

As much of the evidence has come from laboratory studies, it is important to investigate the extent to which these studies reproduce the real cyclomorphic conditions occurring in nature. Laboratory studies have indicated that induction of extreme morphological changes requires the animals to be exposed to several proximate factors simultaneously. However, information is still lacking, since most experiments have involved exposure to one or, at the most, several cyclomorphic factors under otherwise constant conditions.

The present study was planned to compare the differences in the potential intensity of cyclomorphogenic factors in the laboratory and in nature. For this, we conducted two experiments in the laboratory and the field at the same time using the small cladoceran Bosmina longirostris and the predacious copepod Acanthocyclops vernalis.

\section{Materials and methods}

The containers used for culturing the animals were 40-ml cylindrical acrylic chambers (Fig. 1). The chambers were designed after drawing the dialysis culture chamber by Watanabe (1987). Membrane filters (47-mm diameter) were used as a permeable boundary between the culture space and the outer environment. In order to estimate the exchange rate of the water through the filters, the rate of diffusion and permeation of an inorganic ion $\left(\mathrm{Na}^{+}\right)$from the outer environment to the inner space was analyzed. A

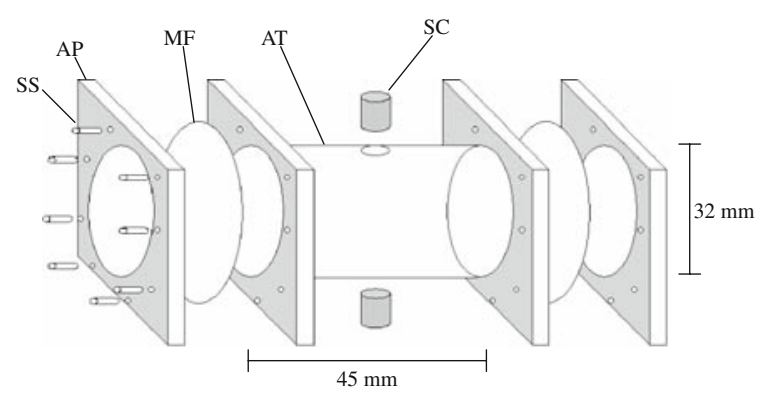

Fig. 1 Structural drawing of the culture chamber. Abbreviations: SS, screw spike; AP, acrylic plate; MF, membrane filter of $47 \mathrm{~mm}$ in diameter; AT, acrylic tube; SC, silicon cap 
chamber filled with aged tap water was placed in a 2-1 glass beaker containing 21 of $\mathrm{NaCl}$ solution $\left(10 \mathrm{mg} \mathrm{l}^{-1}\right)$. The beaker was kept at $20^{\circ} \mathrm{C}$ under static conditions, and the $\mathrm{Na}^{+}$concentration inside and outside the chamber was monitored for $24 \mathrm{~h}$.

A single clone of Bosmina longirostris, originally from Lake Suwa, Japan $\left(36^{\circ} 2^{\prime} \mathrm{N}, 138^{\circ} 5^{\prime} \mathrm{E}\right)$, was used as the test organism. A copepod, Acanthocyclops vernalis, was prepared as the predator because it is a dominant invertebrate predator co-existing in Lake Suwa. Adult females of A. vernalis (body length: $>1.2 \mathrm{~mm}$ ) were isolated from plankton samples collected from Lake Suwa and maintained for $24 \mathrm{~h}$ at $15^{\circ} \mathrm{C}$ until the start of the experiment with natural zooplankton including Bosmina as food.

Two experiments were then started at the same time, one in the laboratory and one in situ. At the beginning of the experiments, 26 groups of B. longirostris, each composed of 20 haphazardly selected adult females, were prepared from the stock culture. Each group was placed in a chamber containing $40 \mathrm{ml}$ aged tap water with Chlorella vulgaris (Chlorella Industry Co. Ltd., Fukuoka, Japan; $2.9 \mu \mathrm{g} \mathrm{C} \mathrm{ml}^{-1}$ ) as food. The food level was settled according to a report for the cladoceran cultures using Chlorella (Nandini \& Sarma, 2003).

The laboratory experiment was conducted under constant conditions $\left(15.0^{\circ} \mathrm{C} ; 16 \mathrm{~h}\right.$ light: $8 \mathrm{~h}$ dark). Twelve chambers were used, with the bosminids being exposed to one of three different treatments, each having four replicates. The first treatment was the control, where each culture chamber was placed into a 500-ml glass beaker containing $300 \mathrm{ml}$ aged tap water plus Chlorella $\left(2.9 \mu \mathrm{g} \mathrm{C} \mathrm{ml}^{-1}\right)$. In the second treatment, to expose the bosminids to Acanthocyclops kairomone, culture chambers were placed into the predator-contaminated beakers, each containing three copepods (outside the chamber). In the third treatment, two individuals of A. vernalis were added to each beaker and an individual copepod was introduced into the culture chamber. Thus, the third treatment involved the bosminids being exposed not only to the kairomone but also to physical contacts with $A$. vernalis. Twenty individuals of Bosmina were added to each beaker as food for the copepods in all treatments. Chlorella was added to each beaker and culture chamber every third day to provide $2.9 \mu \mathrm{g} \mathrm{C} \mathrm{ml}^{-1}$.

The other 15 culture chambers were used for the field experiment, employing treatments similar to those in the laboratory experiment. As a control, five chambers were interconnected with nylon strings and placed in an occlusive polyethylene container filled with 91 temperature-regulated aged tap water at $15^{\circ} \mathrm{C}$. In the central area of Lake Suwa (approximately 6-m depth), the container was suspended from mooring buoy by a $3-\mathrm{m}$ rope with weights to keep the animals at a fixed depth. For the predator treatments, five pairs of chambers were suspended at 3-m depth from the surface water by a rope, with an individual of A. vernalis introduced into one of each of the paired chambers. The bosminids were therefore exposed to the physical stimuli from the predators and the lake water or to the lake water alone. Chlorella cells were added every third day as in the laboratory experiment.

Both experiments were terminated on day 13 and all the animals in each chamber were preserved with sugar-containing formalin at a final concentration of 4\% (Haney \& Hall, 1973). Environmental factors (water temperature and dissolved oxygen concentration) and the density and vertical distributions of the animals were monitored in the central area of the lake on days 1, 7, and 13. Water temperature and dissolved oxygen concentration were monitored from the surface to near the bottom $(6 \mathrm{~m})$ at 1-m intervals using a YSI 55 dissolved oxygen meter (YSI Co., Ohio, USA). Analysis of animal density was done on a column of water by a column sampler (diameter $5.5 \mathrm{~cm}$, length $2 \mathrm{~m}$ ) with a hydraulically operated flap at the bottom to collect three separate samples (surface to $2 \mathrm{~m} \mathrm{depth}, 2-4 \mathrm{~m}$, and $4 \mathrm{~m}$ to near bottom) and then pooling them (total $12.4 \mathrm{l}$ ). The vertical distribution was analyzed using a Van Dorn Sampler with 61 of lake water taken at 1-, 3- and 5-m depth. The animals were collected on a filter (mesh size $40 \mu \mathrm{m}$ ) and preserved with sugar-containing formalin at a final concentration of $4 \%$. Cyclopoid copepods and B. longirostris were identified and counted using a microscope at $100 \times$ magnification.

The specimens of bosminids were divided into two groups for counting: adults and juveniles. Morphotypes (antennule types) of adult females were identified following the criterion used previously (Sakamoto et al., 2007), where animals with hooked antennules were identified as "cornuta," and animals having slightly curved antennules as "pellucida." The identification was not needed for the juveniles because all the individuals showed the "pellucida"morphotype. Differences in morphotype composition 
among the treatments/experiments were tested statistically with the Tukey-Kramer post hoc test (following analysis with ANOVA) for the values of relative abundance of "pellucida" (number of "pellucida": total adult females) after arcsine transformation using StatView version 5 (SAS Institute, Cary, NC, USA). In addition, all the individuals in both experiments had the lengths of body, antennule, and mucrone length recorded under a binocular microscope to the nearest $10 \mu \mathrm{m}$. In order to assess the effects of the treatments, quantitative differences in morphological measurements among the six treatments (three treatments in each experiment) were also tested by nested ANOVA for each of the four divided body size classes: <300, 300-349, 350-399, and $>399 \mu \mathrm{m}$. Body length of $300 \mu \mathrm{m}$ is critical boundaries to divide the animals into juveniles or adults for this Bosmina clone.

\section{Results}

The validity of the culturing chamber was verified by the experiment using an inorganic ion, $\mathrm{Na}^{+}$(Fig. 2). The concentration of $\mathrm{Na}^{+}$in the culture chamber reached a similar value to the outer environment within $16 \mathrm{~h}$. This suggests that chemicals dissolved in the water could permeate the chamber completely by the end of a day.

The lake water temperature and DO concentration were constant down to $4 \mathrm{~m}$ but declined slightly below this depth (Fig. 3a). The mean water

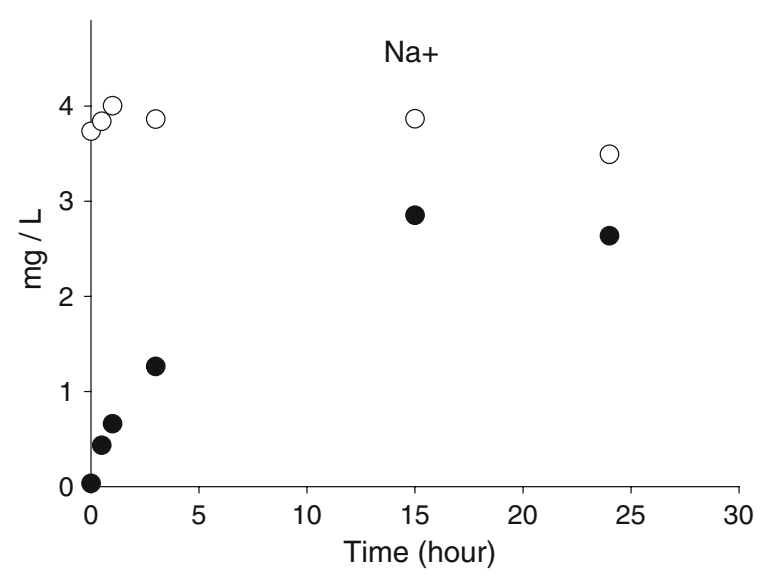

Fig. 2 Temporal changes of $\mathrm{Na}^{+}$ion concentrations inside (solid circle) and outside (open circle) of the culture chamber temperature and DO concentration at 3-m depth were $11.2^{\circ} \mathrm{C}$ and $10.9 \mathrm{mg}^{-1}$, respectively. The temperature of $11.2^{\circ} \mathrm{C}$ was less than that in the laboratory experiment $\left(15^{\circ} \mathrm{C}\right)$. The density of $B$. longirostris was influenced by depth with the density highest near the surface (Fig. 3b). The density of the cyclopoid copepod Thermocyclops taihokuensis was high, but that of Acanthocyclops vernalis was very low irrespective of depth.

At the end of the experiment, the numbers of Bosmina in the culture chambers differed between the treatments/experiments (Table 1). The values for both juveniles and adults tended to be higher in the laboratory than in the field (Table 2). The size at first maturation of Bosmina (smallest body size holding eggs) differed markedly between laboratory and field.

The relative abundances of "pellucida"-morphed Bosmina differed depending on the experimental treatment (Tables 1 and 2). In the laboratory controls, all the animals had "cornuta"-type antennules. However, the percentage of the "pellucida"-morphed individuals tended to be higher in the "physical contact" treatments, although there was no significant difference among the treatments within each experiment. Nevertheless, the value for the "physical contact" treatment in the field experiment was higher than for the "control" and the "kairomone" treatment in the laboratory experiment. The lengths of antennule and mucrone did not differ significantly between treatments in any body size class, although there was a trend for higher values when the animals were exposed to physical contact with predators (Fig. 4).

\section{Discussion}

The number of Bosmina in the chambers was more numerous in the laboratory than in the field (Tables 1 and 2). This may be explained by the difference in temperature between the laboratory and field. The mean temperature of $11.2^{\circ} \mathrm{C}$ at 3-m depth in the lake, where the culture chambers were attached, was lower than that in the laboratory (Table 2; Fig. 3). The different temperatures must cause differences in the growth rates between the bosminids in the laboratory and field. The individual growth rate and egg development times are strongly related to temperature, as expressed by an equation of Bottrell (1975): $\ln D=\ln a+b(\ln T)^{2}$, where $D$ is the duration of 
Fig. 3 (a) Environmental factors and (b) vertical distributions of Bosmina longirostris and adult cyclopoid copepods in lake water during the experiment $($ mean $\pm \mathrm{SE})$ (a) Environmental factors

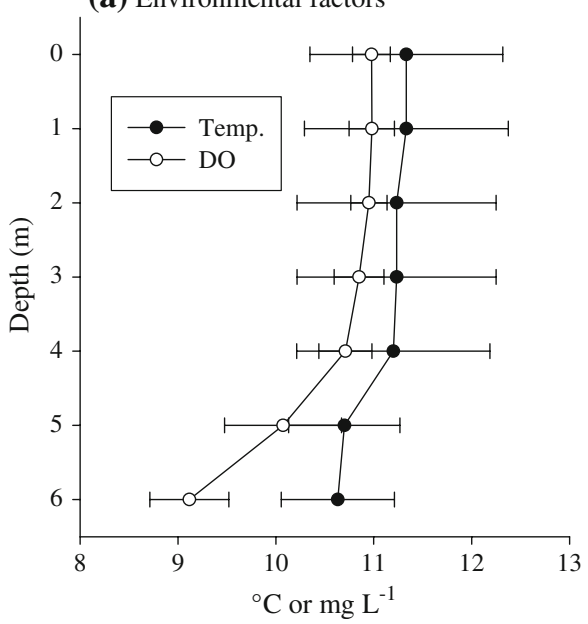

(b) Zooplankton

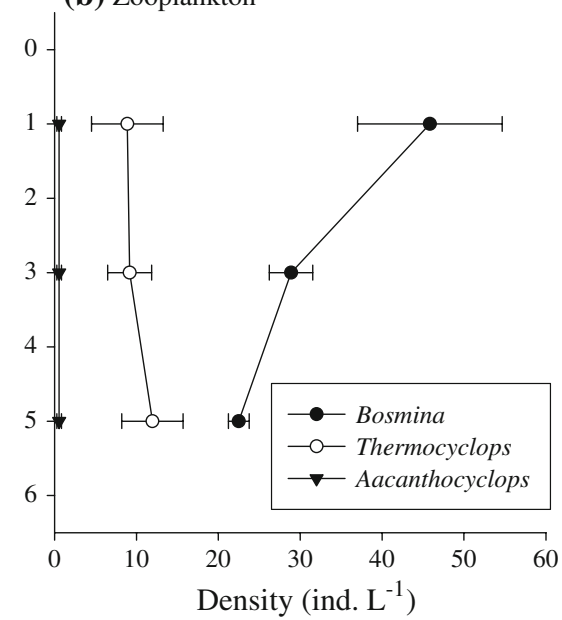

Table 1 ANOVA table: effects of the experimental treatments on B. longirostris

\begin{tabular}{lccr}
\hline Observed number or ratio & df & $F$-value & $P$-value \\
\hline Within culture chambers & & & \\
$\quad$ Total & 5 & 6.166 & 0.0015 \\
$\quad$ Juvenile & 5 & 5.880 & 0.0019 \\
$\quad$ Adult & 5 & 3.238 & 0.0279 \\
$\quad$ "Pellucida" (\%) within adult & 5 & 5.050 & 0.0041 \\
Including wild animals & & & \\
$\quad$ "Pellucida" (\%) within adult & 6 & 11.399 & $<0.0001$ \\
\hline
\end{tabular}

df, Degree of freedom egg development or age at first parturition in days and $T$ is the temperature $\left({ }^{\circ} \mathrm{C}\right)$. For the calculation of age at first parturition, the constant numbers $\ln a$ and $b$ are approximately 3.3 and -0.19 , respectively, for B. longirostris (Hanazato \& Yasuno, 1985). In order to apply these values to the present results, $D$ must be 1.3 times longer in the field $(T=11.2, D=9.1)$ than in the laboratory $(T=15.0, D=6.9)$, resulting in higher population growth rate in laboratory cultures, in which, then, established larger population.

In the "physical contact" treatments, despite the bosminids being exposed to copepod predation, there

Table 2 Effects of the kairomone and physical stimuli from Acanthocyclops on B. longirostris

\begin{tabular}{|c|c|c|c|c|c|}
\hline \multirow{2}{*}{$\begin{array}{l}\text { Location } \\
\text { Temperature }\left({ }^{\circ} \mathrm{C}\right)\end{array}$} & \multirow[t]{2}{*}{ Treatment } & \multicolumn{3}{|c|}{ Observed number $^{\mathrm{a}}$} & \multirow[t]{2}{*}{ "Pellucida" (\%) within adult } \\
\hline & & Total & Juvenile & Adult $^{\mathrm{b}}$ & \\
\hline Field & Wild animals & $27.6(3.7)^{\mathrm{c}}$ & $8.1(3.2)^{\mathrm{c}}$ & $19.4(3.9)^{\mathrm{c}}$ & $31.0(6.7) \mathrm{a}$ \\
\hline \multirow[t]{3}{*}{$11.2(1.8)$} & Control & $26.7(5.0) \mathrm{AB}$ & $6.0(2.0) \mathrm{ab}$ & 20.7 (3.8) $\mathrm{AB}$ & $5.3(1.2) \mathrm{bc}$ \\
\hline & Kairomone & $18.2(2.7) \mathrm{A}$ & $2.6(0.6) \mathrm{a}$ & $15.6(2.6) \mathrm{A}$ & $4.8(1.4) \mathrm{bc}$ \\
\hline & Physical contact & $17.4(2.6) \mathrm{A}$ & $1.8(0.6) \mathrm{a}$ & $15.6(2.7) \mathrm{A}$ & $14.0(3.9) \mathrm{b}$ \\
\hline Laboratory & Control & $30.5(5.4) \mathrm{AB}$ & $10.5(3.1) \mathrm{ab}$ & $20.0(3.5) \mathrm{AB}$ & $0 \mathrm{c}$ \\
\hline \multirow[t]{2}{*}{15.0 (constant) } & Kairomone & $42.5(6.0) \mathrm{B}$ & $13.3(3.7) \mathrm{b}$ & $29.3(2.4) \mathrm{B}$ & $0.9(0.9) \mathrm{c}$ \\
\hline & Physical contact & $37.8(4.2) \mathrm{B}$ & $13.8(2.5) \mathrm{b}$ & $24.0(3.0) \mathrm{AB}$ & $7.2(2.6) \mathrm{bc}$ \\
\hline
\end{tabular}

a Numbers represent the mean values $( \pm \mathrm{SE})$

b Adult: body length $\geq 250 \mu \mathrm{m}$ for wild animals and $\geq 300 \mu \mathrm{m}$ for laboratory-cultured ones (size at first maturation differed markedly between the wild and laboratory-cultured Bosmina)

c Mean densities (inds $1^{-1}$ ) in Lake Suwa

Values denoted by the same letters are not significantly different each other (Tukey-Kramer post hoc test, $P>0.05$ ) in numbers of total individuals, juveniles, adults, and "pellucida" (\%) in the chambers set in field and in the laboratory 

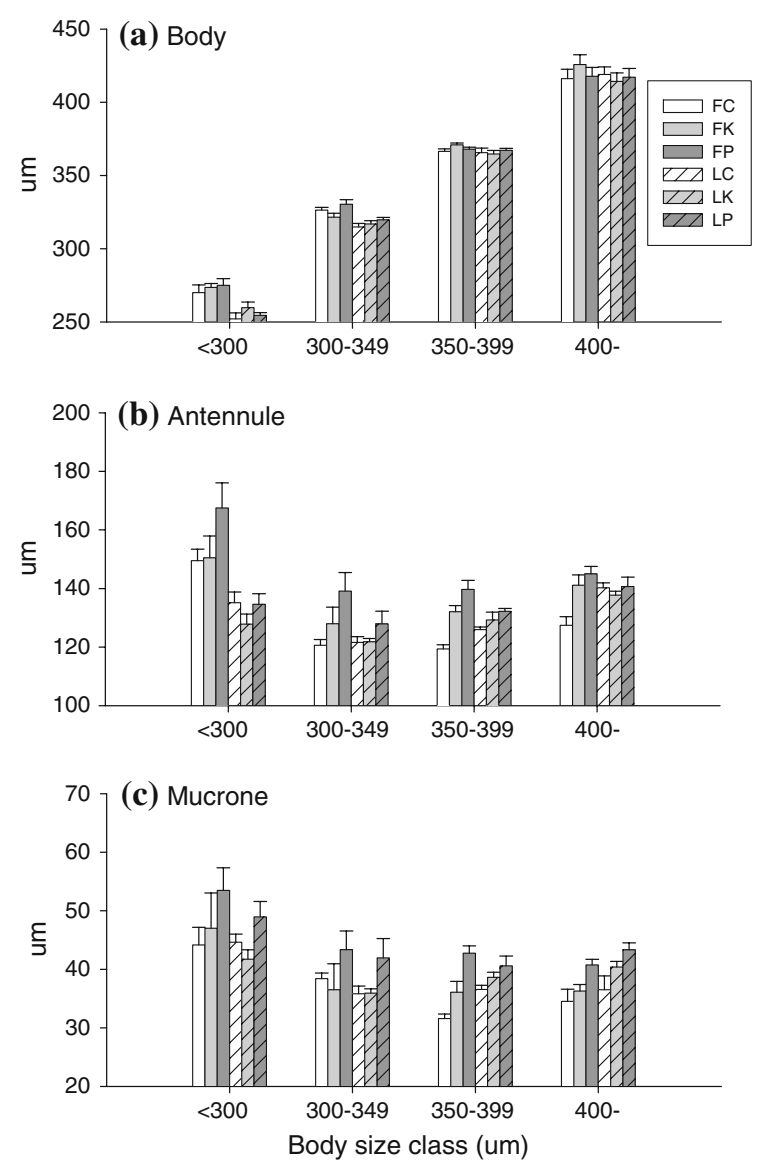

Fig. 4 Lengths of body (a), antennule (b), and mucrone (c) of Bosmina in each treatment (mean $\pm \mathrm{SE}$ ). Abbreviations: $\mathrm{F}$, field; L, laboratory; C, control, K, kairomone; P, physical contact

was no strong decline in population density in either experiment. These results suggest that the individual death rate of $B$. longirostris due to copepod predation was not high, in agreement with the previous studies (Sakamoto \& Hanazato, 2008).

During our experiments, the dominant predator in the lake was the small Cyclopoida, Thermocyclops taihokuensis, while the density of Acanthocyclops vernalis was very low (Fig. 3). Although these two copepods are known to influence the community structure and population dynamics of small zooplankters including Bosmina, the predation impact on the prey organisms is more severe with Acanthocyclops than with Thermocyclops (Nagata \& Hanazato, 2006). However, the densities of the copepods recorded from the daytime samplings might not necessarily represent the actual abundance in the field. This was because we did not take the diel vertical migration (DVM) of the copepods into consideration (Williamson \& Magnien, 1982; Neill, 1990; Makino \& Ban, 1998). Chang \& Hanazato (2004) have observed the vertical distributions of cyclopoid copepods in Lake Suwa, and have shown that the individuals in a large part of the cyclopoid copepod population stay just above the bottom during the day and migrate upward at night. Our zooplankton sampling method with the column sampler most probably failed to include cyclopoid copepods distributed closely to the bottom. On the other hand, the prey Bosmina shows no diel changes in distribution in this lake (Chang, 2003). Thus, vertical migration by the copepods can cause a difference between day and night in the predation pressure on Bosmina in the mid- or upper layers.

Size at first maturation of Bosmina (smallest body size holding eggs) was smaller in the wild animals than in the laboratory-cultured clone (caption in Table 2). Such phenomenon has often been observed in the field, in which $B$. longirostris matures at smaller size in summer and autumn than the other seasons (Kerfoot, 1974; Brock, 1980). This coincides with the present observation in autumn (October). The seasonal succession in body length may be a result of complicated effects of size-selective predation, genotypic succession, and fish-induced life history sift (Kerfoot, 1974; Brock, 1980; Tollrian and Dodson, 1999).

Factors related to cyclopoid copepods are known to enhance the development of the protuberant morphology in B. longirostris (Kerfoot, 1987; Kappes \& Sinsch, 2002, Sakamoto et al., 2007). Kairomones (chemical signals) are the most prevailing signals used in prey-predator interactions in freshwater plankton (Lass \& Spaak, 2003). Since the predator kairomones are dissolved in the water body, they help the prey animals to take preventive measures (elongation of appendages), as they can detect the presence of the predators before any encounter (Hanazato, 1994). Recently, however, it has been found that the physical factors caused by mechanical attacks/handling by the copepods are additional cues enhancing the development of the anti-predator morphology in Bosmina longirostris: the "cornuta"-morphed animals (hooked antennules) change their antennule shape to the "pellucida"morphotype (slightly curved antennules) (Sakamoto 
et al., 2007). The "pellucida"-type antennules defend the bosminid's ventral opened carapace against copepod predation (Kappes \& Sinsch, 2002; Chang \& Hanazato, 2003; Sakamoto \& Hanazato, 2008).

The relative abundance of the "pellucida"-morphed adults tended to be higher in the culture chambers in the lake than in the laboratory (Table 2). All the bosminid individuals of the laboratorycultured clone had "cornuta"-morphed antennules in their adult stages under constant laboratory conditions without predators (control in the laboratory experiment, Table 2). However, the percentage value for "pellucida" increased significantly to $14.0 \%$ when these were exposed to physical contacts with the predators in the lake, clearly in accord with the results of our previous study (Sakamoto et al., 2007). Although the value was also high in the laboratory experiment $(7.2 \%)$, the increase was not significant.

Selective predation by the copepods against "cornuta"-morphed individuals can be a factor that raises the ratio of the "pellucida"-morphed individuals in population. However, this was not the event that occurred in the present study since the copepod predation pressure was very low (no reduction in observed numbers, Table 2). The high abundance of "pellucida"-morphed individuals recorded only in the field experiment indicates that some latent factors other than the chemical (kairomone) and physical (mechanical contact) signals from the predators, influenced the bosminid's antennule shapes in the natural environment.

Difference in induction efficiency between the laboratory and field experiments can be explained by differences in water temperature. During our experiment, the lake water temperature of $11.2^{\circ} \mathrm{C}$ was lower than that in the laboratory $\left(15.0^{\circ} \mathrm{C}\right)$. Several researchers have demonstrated that water temperature affects not only growth but also the morphology of cyclomorphic cladocerans (Kerfoot, 1975, 2006; Havel \& Dodson, 1985; Kappes \& Sinsch, 2002). Kappes \& Sinsch (2002) reported that acclimation of B. longirostris individuals to cold water $\left(10^{\circ} \mathrm{C}\right.$ in their experiment) led to an increase in appendage length. A similar trend was observed in the present study (Fig. 4b, c). Although the difference was not significant, juvenile individuals in particular tended to have longer appendages in the field experiment, where the animals were exposed to a lower temperature $\left(11.2^{\circ} \mathrm{C}\right)$ than in the laboratory $\left(15.0^{\circ} \mathrm{C}\right)$
(Fig. 4b, c). Moreover, it was observed in the present study that some Bosmina individuals had the "pellucida"-morphed antennules even in the absence of chemical/physical signals from the predators when they were placed in the field (control in the field experiment, Table 2), which was not observed in the laboratory experiment. This indicates that the colder water lead to a change of antennule shape in this species.

The relative abundance of the "pellucida"-type animals was far higher in the wild $(31 \%)$ than in the clonal populations used in the experiments $(14 \%$ at maximum) (Table 2). One possible reason to explain the difference between the wild animals and in the clonal populations is the selective predation of the copepods on the "cornuta"-morphed animals in the field (Kappes \& Sinsch, 2002). In some clones, each antennule morphotype is genetically fixed and the "cornuta"-morphed individuals are more vulnerable to the copepod predation (Kappes \& Sinsch, 2002). On the other hand, Sakamoto et al. (2007) have reported that the "pellucida"-type antennule of B. longirostris is induced only when the animals were exposed to mechanical contact with the copepods. Therefore, the relative abundance of each morphotype in the natural environment can be regulated by selective predation in combination with the inducible defense mechanisms of the prey Bosmina.

The previous studies have revealed that changes in bosminids' antennule length and shape are governed by different signals from predators: chemical signals (kairomones) induce the elongation of antennules, while antennule shapes are affected by physical signals (mechanical contacts/attacks) (Kappes \& Sinsch, 2002; Sakamoto et al., 2007). However, results of the present study suggest that lower temperature enhances both the morphological changes. The lower temperature can be effective in helping prey bosminids to detect a severe predation threat by cyclopoid copepods, since that condition is a feature of spring and fall, a time when copepods are abundant (Kerfoot, 1975; Chang \& Hanazato, 2003). Therefore, it can be concluded that the low temperature is a key factor inducing the developments of anti-predator morphologies in Bosmina.

The present study has shown that the small culture chamber (Fig. 1) is an excellent tool for investigating the cyclomorphic conditions existing in natural water 
bodies. Linking natural and artificial environments using experimental approaches seems to be an appropriate avenue for clarifying the nature of phenomena occurring in the field.

Acknowledgments The authors thank Mr. J. Y. Ha, Dr. T. Nagata, and Dr. K.H. Chang for their helpful comments on our work. This study was partly supported by Grants-in-Aid to M. Sakamoto and T. Hanazato (1910361) from JSPS Research Fellowship for young Scientist, Grants-in-Aid to T. Hanazato (no. 17201012) from Japan Society for the promotion of Science, and a research fund to $T$. Hanazato from the ExTEND2005 project of the Ministry of Environment, Japan.

\section{References}

Agrawal, A. A., 2001. Phenotypic plasticity in the interactions and evolution of species. Science 294: 321-326.

Bottrell, H. H., 1975. The relationship between temperature and duration of egg development in some epiphytic Cladocera and Copepoda from the River Thames, Reading, with a discussion of temperature functions. Oecologia 18: $63-84$

Brock, D. A., 1980. Genotypic succession in the cyclomorphosis of Bosmina longirostris (Cladocera). Freshwater Biology 10: 239-250.

Brown, W. L. Jr., T. Eisner \& W. H. Whittaker, 1970. Allomones and kairomones: transspecific chemical messengers. BioScience 20: 21-22.

Chang, K. H., 2003. Role of predation in structuring zooplankton community in Lake Suwa. Ph.D thesis, Shinshu University, $257 \mathrm{pp}$.

Chang, K. H. \& T. Hanazato, 2003. Seasonal and reciprocal succession and cyclomorphosis of two Bosmina species (Cladocera, Crustacea) co-existing in a lake: their relationship with invertebrate predators. Journal of Plankton Research 25: 141-150.

Chang, K. H. \& T. Hanazato, 2004. Diel vertical migrations of invertebrate predators (Leptodora kindtii, Thermocyclops taihokuensis, and Mesocyclops sp.) in a shallow, eutrophic lake. Hydrobiologia 528: 249-259.

Hanazato, T., 1994. Kairomone-mediated predator-prey relationship in lake zooplankton communities. Japanese Journal of Ecology 44: 61-77 (in Japanese).

Hanazato, T. \& T. Ooi, 1992. Morphological responses of Daphnia ambigua to different concentrations of a chemical extract from Chaoborus flavicans. Freshwater Biology 27: 379-385.

Hanazato, T. \& M. Yasuno, 1985. Effect of temperature in the laboratory studies on growth, egg development and first parturition of five species of Cladocera. Japanese Journal of Limnology 46: 185-191.

Haney, J. F. \& D. J. Hall, 1973. Sugar coated Daphnia: a preservation technique for Cladocera. Limnology and Oceanography 18: 331-333.

Havel, J. \& S. I. Dodson, 1985. Environmental cues for cyclomorphosis in Daphnia retrocurva Forbes. Freshwater Biology 15: 469-478.
Kappes, H. \& U. Sinsch, 2002. Temperature- and predatorinduced phenotypic plasticity in Bosmina cornuta and B. pellucida (Crustacea: Cladocera). Freshwater Biology 47: 1944-1955.

Kerfoot, W. C., 1974. Egg-size cycle of a cladoceran. Ecology 55: $1259-1270$.

Kerfoot, W. C., 1975. Seasonal changes of Bosmina (Crustacea, Cladocera) in Frains Lake, Michigan: laboratory observations of phenotypic changes induced by inorganic factors. Freshwater Biology 5: 227-243.

Kerfoot, W. C., 1987. Translocation experiment: Bosmina responses to copepod predation. Ecology 68: 596-610.

Kerfoot, W. C., 2006. Baltic Eubosmina morphological radiation: Sensitivity to genetic differences. Archives of Hydrobiology 167: 147-168.

Laforsch, C., L. Beccara \& R. Tollrian, 2006. Inducible defenses: the relevance of chemical alarm cues in Daphnia. Limnology and Oceanography 51: 1466-1472.

Laforsch, C., W. Ngwa, W. Grill \& R. Tollrian, 2004. An acoustic microscopy technique reveals hidden morphological defenses in Daphnia. Proceedings of National Academy of Science, USA 101: 15911-15914.

Laforsch, C. \& R. Tollrian, 2004. Extreme helmet formation in Daphnia cucullata induced by small-scale turbulence. Journal of Plankton Research 26: 81-87.

Lass, S. \& P. Spaak, 2003. Chemically induced anti-predator defences in plankton: a review. Hydrobiologia 491: 221239.

Makino, W. \& S. Ban, 1998. Diel changes in vertical overlap between Cyclops strenuous (Copepoda; Cyclopoida) and its prey in oligortophic Lake Toya, Hokkaido, Japan. Journal of Marine Systems 15: 139-148.

Nagata, T. \& T. Hanazato, 2006. Different predation impacts of two cyclopoid species on a small-sized zooplankton community: an experimental analysis with mesocosms. Hydrobiologia 556: 233-242.

Nandini, S. \& S. S. S. Sarma, 2003. Population growth of some genera of cladocerans (Cladocera) in relation to algal food (Chlorella vulgaris) levels. Hydrobiologia 491: 211-219.

Neill, W. E., 1990. Induced vertical migration in copepods as a defence against invertebrate predation. Nature 345: 524526.

Sakamoto, M., K. H. Chang \& T. Hanazato, 2006. Inhibition of development of anti-predator morphology in the small cladoceran Bosmina by an insecticide: impact of an anthropogenic chemical on prey-predator interactions. Freshwater Biology 51: 1974-1983.

Sakamoto, M., K. H. Chang \& T. Hanazato, 2007. Plastic phenotypes of antennule shape in Bosmina longirostris controlled by physical stimuli from predators. Limnology and Oceanography 52: 2072-2078.

Sakamoto, M. \& T. Hanazato, 2008. Antennule shape and body size of Bosmina: key factors determining its vulnerability to predacious Copepoda. Limnology 9: 27-34.

Stabell, O. B., F. Ogbebo \& R. Primicerio, 2003. Inducible defences in Daphnia depend on latent alarm signals from conspecific prey activated in predators. Chemical Senses 28: 141-153.

Tollrian, R. \& S. I. Dodson, 1999. Inducible defenses in Cladocera: constrains, costs, and multipredator environments. In Tollrian, R. \& C. D. Harvell (eds), The Ecology 
and Evolution of Inducible Defenses. Princeton University Press: 177-202.

Tollrian, R. \& C. Laforsch, 2006. Linking predator kairomones and turbulence: synergistic effects and ultimate reasons for phenotypic plasticity in Daphnia cucullata. Archives of Hydrobiology 167: 135-146.

Vos, M., W. Kooi, D. L. DeAngelis \& M. Mooij, 2004. Inducible defences and the paradox of enrichment. Oikos 105: 471-480.
Watanabe, Y., 1987. The use of dialysis culture chamber to measure N/C and $\mathrm{P} / \mathrm{C}$ ratios of individual phytoplankton species. Japanese Journal of Limnology 48: 137-140.

Williamson, C. E. \& R. E. Magnien, 1982. Diel vertical migration in Mesocyclops edax: implications for predation rate estimates. Journal of Plankton Research 4: 329-339. 